\title{
Safety Heart Rate Vest Prototype by using Pulse Heart Rate Sensor and Global Positioning System for Surface Mining
}

\author{
Muhammad Akbar Musseng \\ Mining Engineering Department \\ Hasanuddin University \\ Makassar, Indonesia \\ Achmad Fachry \\ Electrical Engineering Department \\ Hasanuddin University \\ Makassar. Indonesia
}

\author{
Alif Tri Handoyo \\ Informatics Engineering Department \\ Hasanuddin University \\ Makassar, Indonesia \\ Aryanti Virtanti Anas \\ Mining Engineering Department \\ Hasanuddin University \\ Makassar, Indonesia
}

\begin{abstract}
Many types of hazards that can occur in mining industry explosions due to high pressure, dangerous gas poisoning, can be caused by occupational diseases in miners. This paper explains about the design safety heart rate vest which is using pulse heart rate sensor and global positioning system. This safety vest will be controlled by website from the result design to control pulse heart rate and position of user safety vest in mining industry. This technology is useful, we used internet sever concept, and using repeater to transfer the information of user safety vest (optional). Surface mining will control and analyzes heart rate condition and position of user for prevent from hazards. The method carried out using the pulse heart rate sensor is connected to Wemos ESP8266 D1 Mini, and the Global Positioning System (GPS) is connected to the ESP266 MCU Node After the circuit, reading the data is forwarded to the website. Reading heart rate sensor data in the form of a graph and shows the user identity. The pulse heart rate sensor experiment is carried out for 3 times, the data obtained by the heart rate ranges from 81 - 93 BPM (Beat Per Minute). Trial location on the surface area in Makassar City, South Sulawesi. The Global Positioning System data that is read on Google Maps.
\end{abstract}

Key Words: Safety Vest, Pulse Heart Rate Sensor, GPS, Repeater.

\section{INTRODUCTION}

Hazardous conditions in the mine environment cause a number of work accidents and cause injury and even loss of human life, damage to property or mining equipment, and disturbances in production [1]. Many types of hazards can occur such as explosions, landslides, or gas poisoning during work. Not only that the danger risks consist of considerable environmental, health and safety risks for the miners [2].

The mining industry has focused on minimizing or reducing the risks or injuries that occur in the mining environment but broadly speaking the statistics of death do not show significant changes for miners. So it is necessary to counter the activities of miners during the mining industry environment, by utilizing pulse heart rate sensor technology to detect the miner's heart rate, while adding the Global Positioning System feature in tracking the last position of the miners through the results of website displays. This Pulse Heart Rate Sensor and Global Positioning System are placed on the safety vest section.

Heart rate is a manifestation of the heart's ability, an indicator of heart rate is a pulse. So to know the work of the heart can be seen from the pulse which is a propagation of the heart rate. To find out the speed of a person's pulse can be done by pulse rate by calculating the sudden change of pressure that is propagated as a wave on the wall of blood [3] Some points of the human body can detect the human pulse by measuring the carotid artery (neck area). It is located in the neck below the ear lobe, where there is a carotid artery running between the trachea and the sternocleidomastoid muscle.

Carotid Pulse (CP) is a pressure signal that is recorded from the carotid artery as it passes near the body surface on the neck. This shows variation in pressure and arterial blood volume with each heartbeat [4].

The use of pulse heart rate sensor is connected by using Wemos to capture signals from the internet server, reading the heart rate data will be read on the website. Likewise with the Global Positioning System (GPS) connected with the MCU Node, the reading of the data will be forwarded to the website that has been designed.

\section{METHODOLOGY}

\section{a. Methodology Diagram}

The execution of this technology starts from creating a website, design safety vest, adjusting the global positioning system, coding google maps, installing and adjusting the Heart Pulse Sensor on the Wemos in this device, setting the device on the server, and arranging repeaters.

\section{b. Creating a Website with HTML and CSS}

Prototype calibration testing will be monitored remotely through the website. Making the main page on the website that will be used for monitoring workers. The main page is based on a design template that has been tested based on User Experience (UX) website users. After that the database will be designed with My SOL and PHP. 


\section{c. Design of Safety Vest}

The design shows the features of a Safety Vest made from canvas fabric and a net mesh fabric whose outer parts will be covered with scot light, on the outside of the safety vest placed a pocket for pulse hear rate sensor and global positioning system that is not too weight so as not to disturb the users of Safety Vest.

\section{d. Adjusting the Global Positioning System (GPS)}

The use of the GPS Module ensures that the GPS program installed on Node MCU runs perfectly.

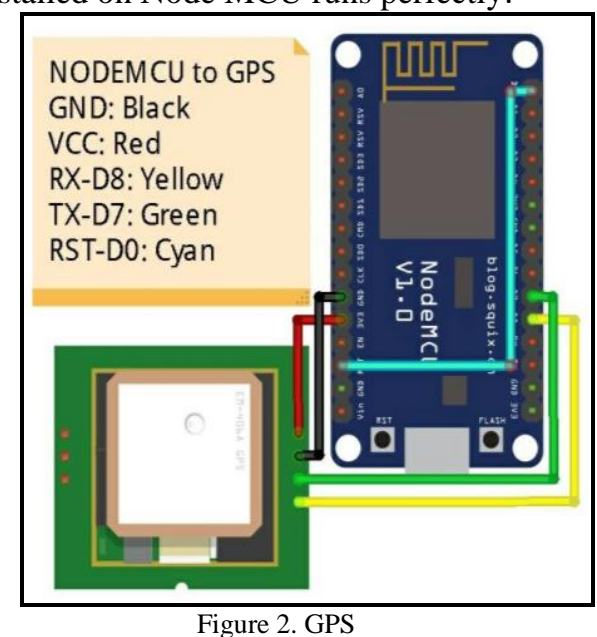

e. Google Maps Coding API

Google maps are chosen to support maps in this system. Google Maps is a map that can be seen using a browser. Designing SAR-VEST can add Google Maps features on the web that will be created with the Google Maps API. The Google Maps API is a library in the form of JavaScript.

f. Install and adjust the Heart Pulse Sensor on the Wemos in this device.

Wemos is activated through a voltage source from a $9 \mathrm{~V}$ DC battery. From the voltage source, Wemos will supply the voltage for the pulse sensor. The voltage will be given by the Wemos by $5 \mathrm{~V}$ and the connection conductor component will get a voltage of $3.3 \mathrm{~V}$. When all components are active, the tool will start working. Pulse sensor will detect heartbeat in humans and then the data is processed by Wemos.

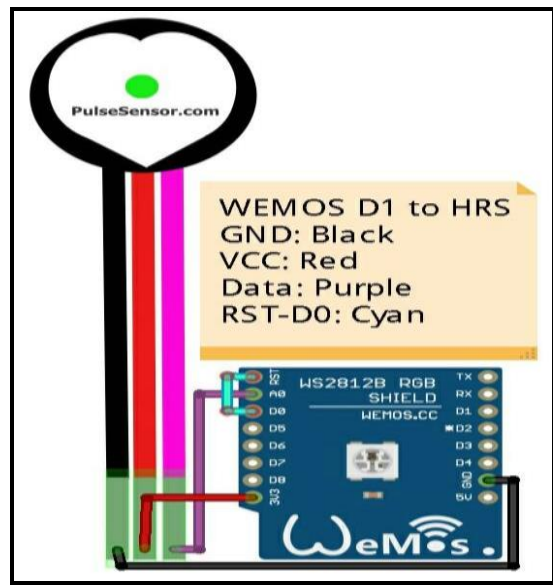

Figure 3. Pulse Heart Rate Sensor g. Device Settings on the Server

Set the device on the Server via computer/Laptop observer, the goal is to remote monitoring in real time. After the device is activated, the device goes into standby mode, which is a condition where the device is ready to receive messages from the devices those are used by the workers. This server device must always be connected to the server website. This website functions as an interface as well as an indicator if there is an emergency, this website also stores data on workers registered therein. If the server device receives an emergency message sent by the worker device, then the server device will display the contents of the emergency message on the website that has been installed on the server computer.

\section{h. Arrange Repeater}

Arranging repeater is based on the signal range connection, if the connection in a location has been low, so in that specific area will be paired by repeater for strength the signal and expand the signal rang.

\section{DISCUSS OF THE RESULT}

\section{a. Block Diagram}

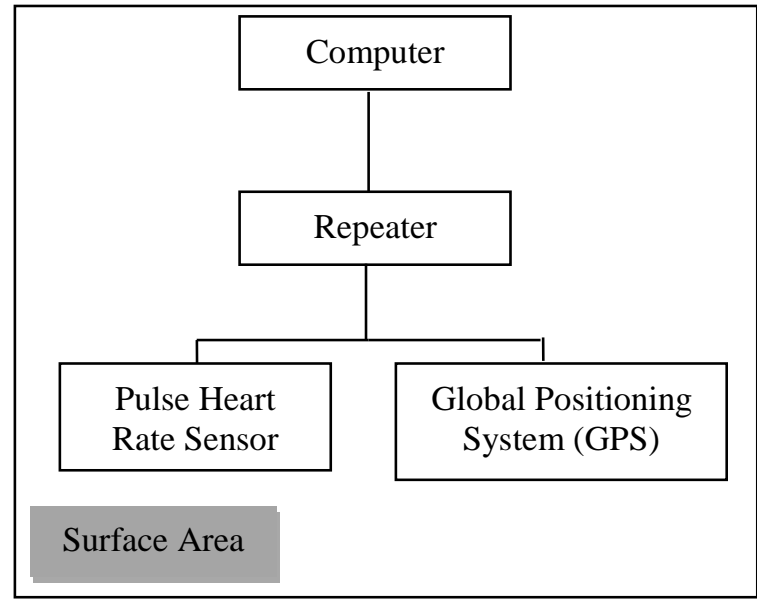

Figure 4. Block Diagram

a. Set of Tools

The implementation is carried out in accordance with the design that has been made before in the system and can activate the control and monitoring functions through the website system settings, the implementation begins with the implementation of hardware.

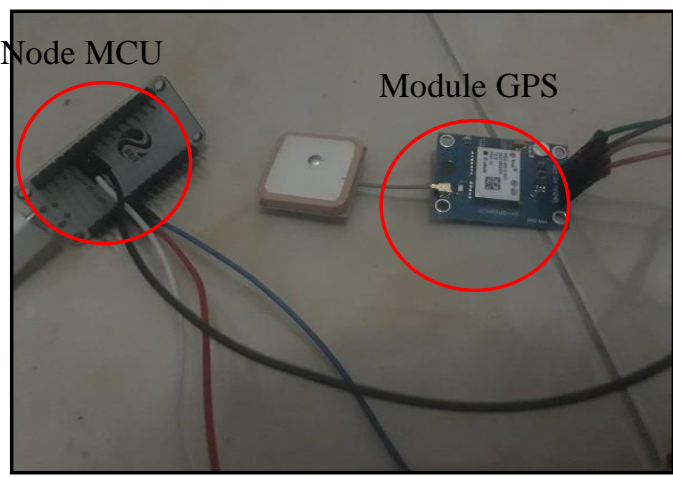

Figure 5. GPS to Node MCU 
In the picture above the black jumper cable is connected to GND, the white cable is connected to the VCC, the blue cable is connected to RX-D8, the red cable is connected to TX-D7.

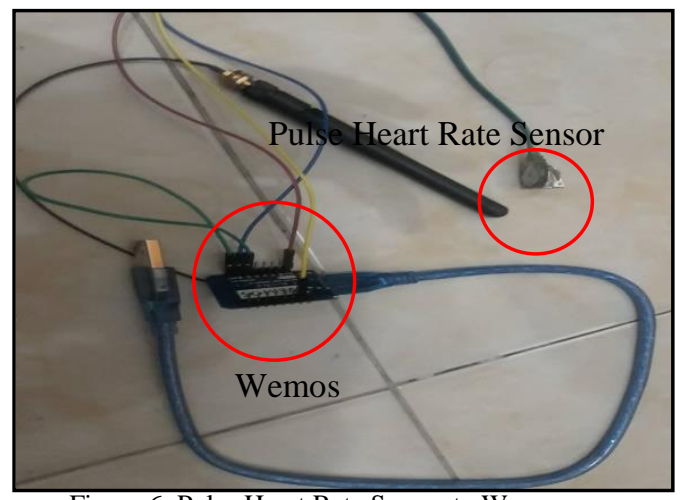

Figure 6. Pulse Heart Rate Sensor to Wemos

In the picture above the yellow jumper cable is connected to GND, the red cable is connected to the VCC, the blue cable is connected to Data, the green color is connected to RST-D0

\section{b. Safety Vest}

The Safety vest consists of Pulse Heart Rate sensor, Node MCU, Wemos, and Module Global Positioning System. Pulse heart rate sensor is used to detect heart rate condition of user. Heart rate sensor attached to the carotid artery (neck).

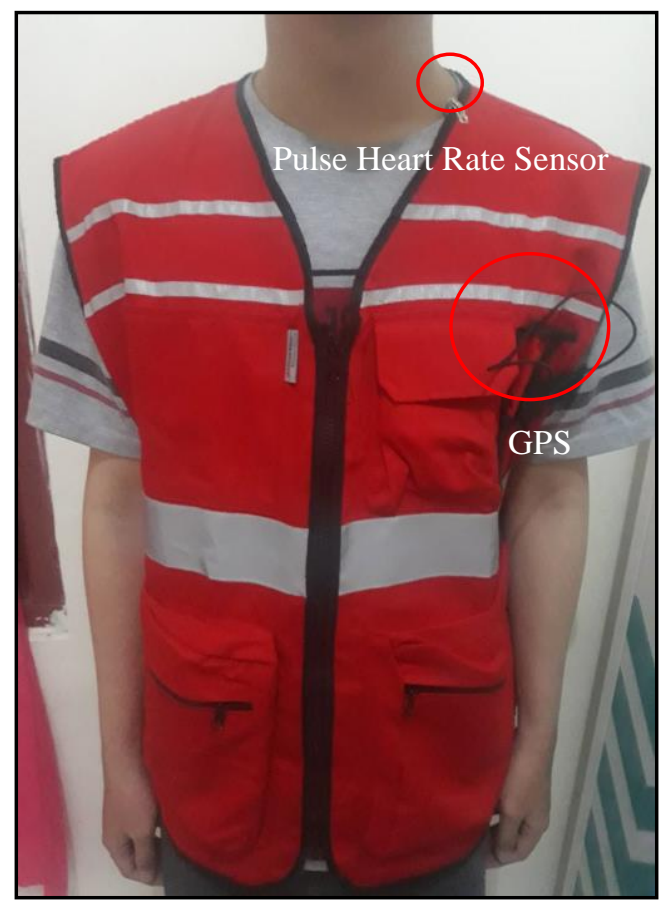

Figure 7. Design of Vest

This vest does not disturb the activities and comfort of the user, if the sensor is attached to the neck. Use this safety vest. c. Hear Rate Sensor Graphic

Heart Rate Sensor has been calibration for one minute, that sensor detect every 15 second.

1. Experiment 1

Table 1. Heart Rate Information (Experiment 1)
\begin{tabular}{|c|c|c|c|c|c|}
\hline \multicolumn{7}{|c|}{ Time } \\
\hline B & $04: 22: 15$ & $04: 22: 30$ & $04: 22: 45$ & $04: 23: 00$ & $04: 23: 10$ \\
P & & & & & \\
\cline { 2 - 6 } M & 93 & 92 & 93 & 91 & 89 \\
\hline
\end{tabular}

Based on the experimental table above shows the range of the heart rate of the vest users range 00-15 seconds obtained 93 BPM, 15-30 seconds obtained 92 BPM, 30-45 obtained 93 BPM, 45-60 seconds obtained 91 BPM, 60-75 seconds obtained 89 BPM ( Beats Per Minute).

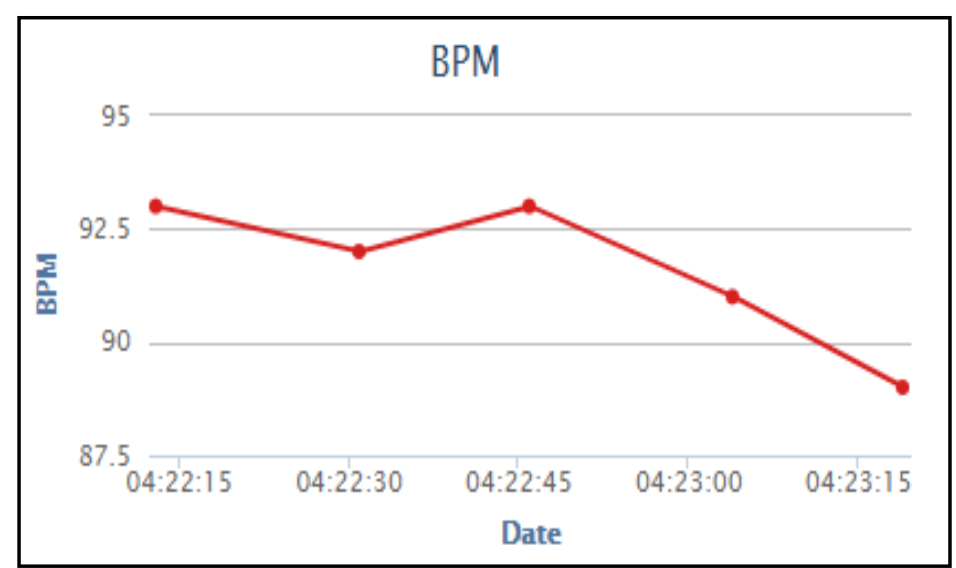

Figure 8. Heart Rate Sensor Graphic (Experiment 1)

\section{Experiment 2}

\begin{tabular}{|c|c|c|c|c|c|}
\hline B & 22:41:30 & $22: 41: 45$ & $22: 42: 00$ & $22: 42: 15$ & 22:42:30 \\
\hline $\mathbf{M}$ & 93 & 91 & 83 & 85 & 81 \\
\hline
\end{tabular}

Based on the experimental table above shows the range of the heart rate of the vest users range 00-15 seconds obtained 93 BPM, 15-30 seconds obtained 91 BPM, 30-45 obtained 83 BPM, 45-60 seconds obtained 85 BPM, 60-75 seconds obtained 81 BPM ( Beats Per Minute). 


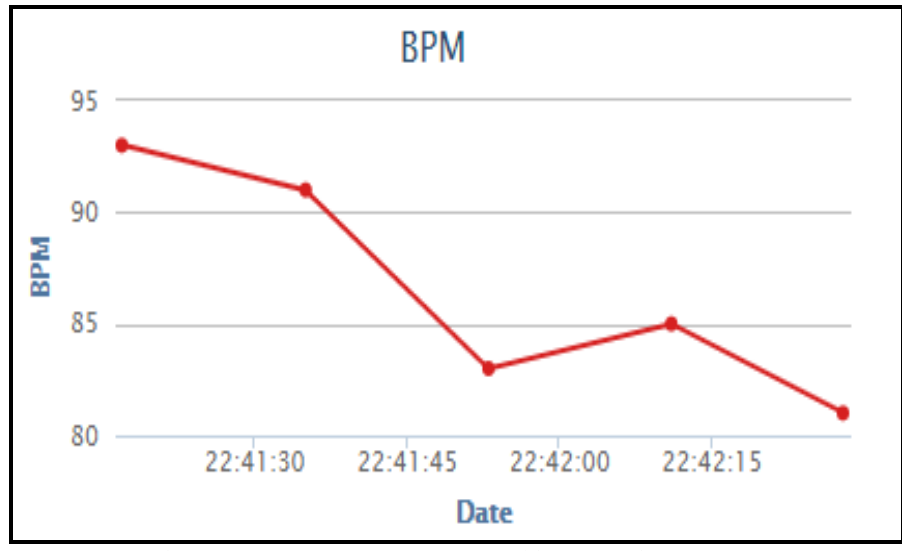

Figure 9. Heart Rate Sensor Graphic (Experiment 2)

\section{Experiment 3}

\begin{tabular}{|c|c|c|c|c|c|}
\multicolumn{6}{c|}{ Table 3. Heart Rate Information (Experiment 3) } \\
\hline B & $23: 25: 15$ & $23: 25: 30$ & $23: 25: 45$ & $23: 26: 00$ & $23: 26: 15$ \\
\cline { 2 - 6 } P & 89 & 90 & 91 & 93 & 93 \\
\hline M & & & & & \\
\hline
\end{tabular}

Based on the experimental table above shows the range of the heart rate of the vest users range 00-15 seconds obtained 89 BPM, 15-30 seconds obtained 90 BPM, 30-45 obtained 91 BPM, 45-60 seconds obtained 93 BPM, 60-75 seconds obtained 93 BPM ( Beats Per Minute).

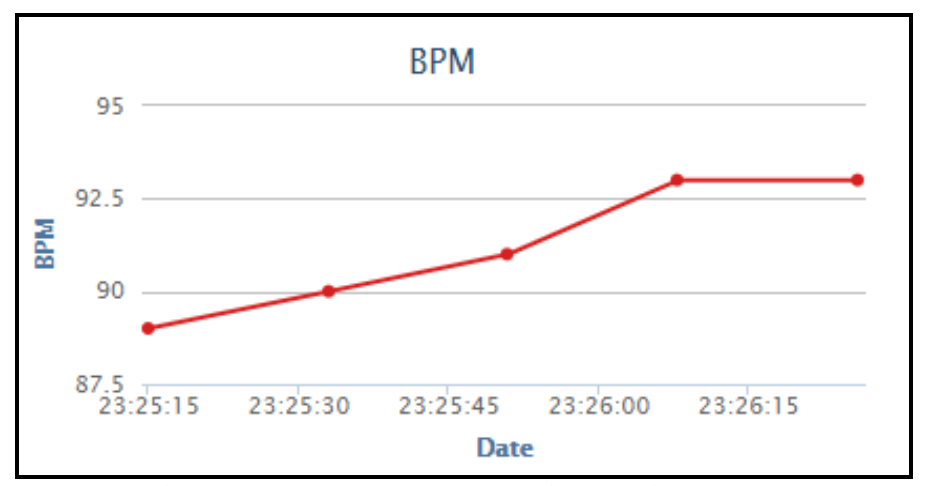

Figure 10. Heart Rate Sensor Graphic (Experiment 3)

These three experiments showed range heart rate sensor data 81-93 Beats Per Minute (BPM). Based on National Health Service data, the average heart rate of adults and seniors is 60-100 Beat Per Minute (BPM). So a series of sensor devices designed to detect heart rate properly.

\section{d. Global Positioning System Data}

The range of GPS distance depends on how far the network connection is transmitted from the server. So that to expand GPS coverage, repeaters are needed as a media to strengthen the signals that are not reached by the server. The following is the display of google maps to detect the location of the user's vest. Figure 11 read the location in the form of a map. Figure 12 read the location in the form of satellite.

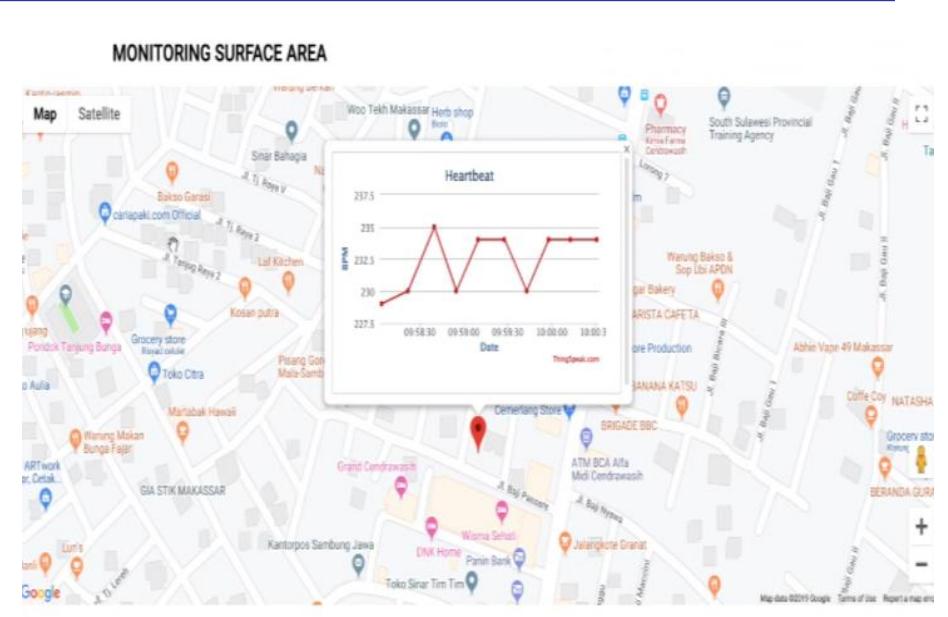

Figure 11. Display Of Google Maps

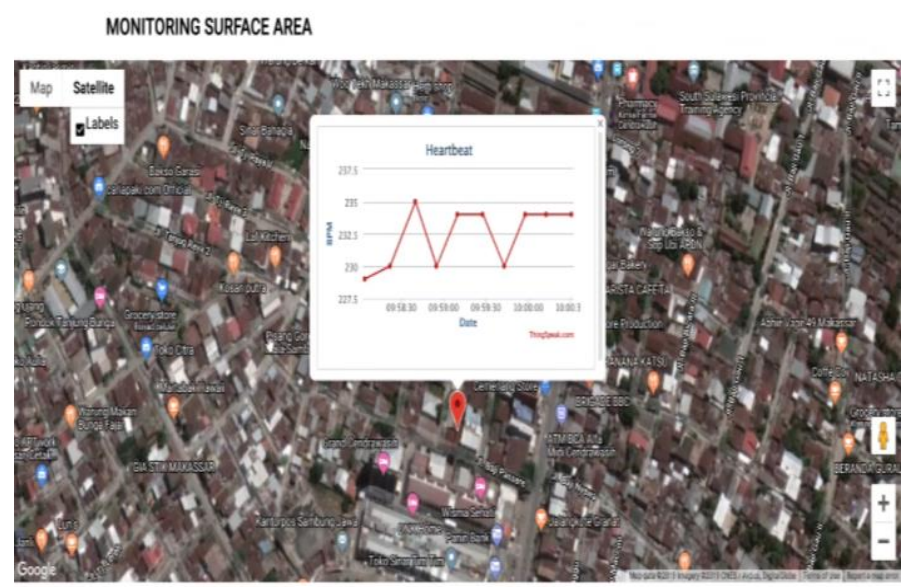

Figure 12. Display of Google Satellite

e. Website

Website design that is made which is also programmed using internet server for surface area (mining) that will detect the worker's location and heart rate.

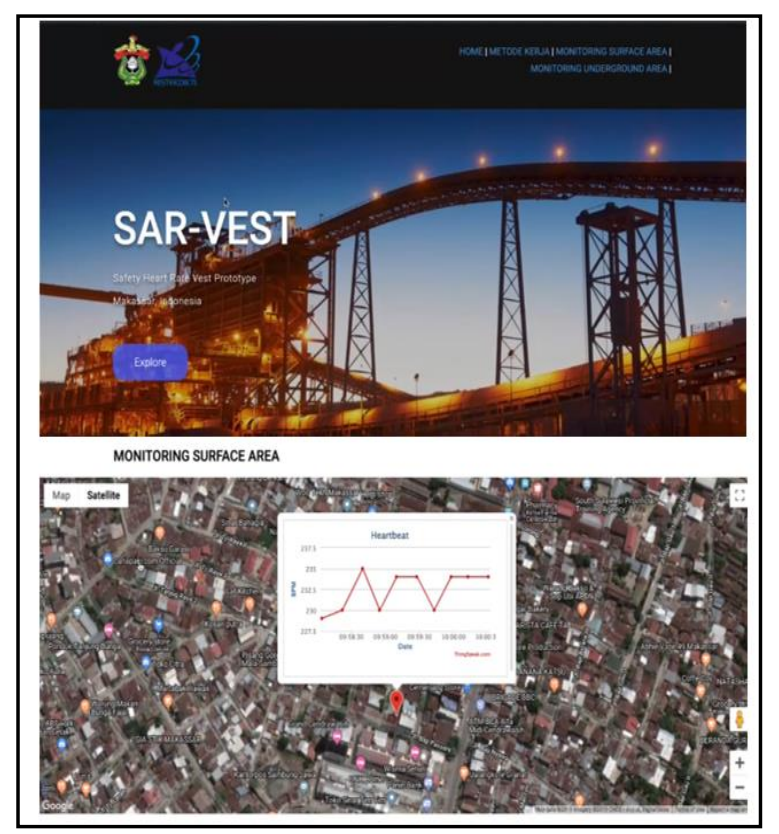

Figure 13. Website 
The website that has been designed will display the user's heart rate in the form of graphics and user identity in general

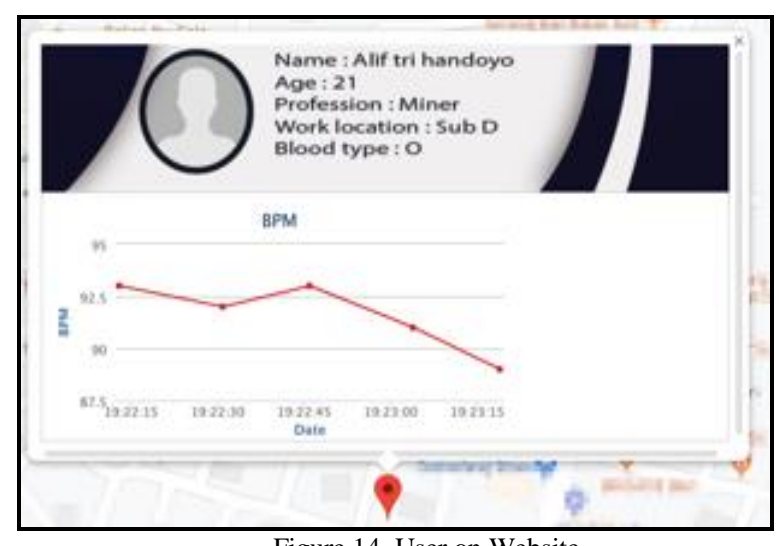

IV. CONCLUSION

Safety vest prototype based on pulse heart rate sensor and global positioning which is controlled through website design results and connected on Google maps, which are useful in mining industries in open mining because it can control the condition of miners and prevention of environmental, health and safety risks.

\section{ACKNOWLEDGMENT}

Thanks a lot for Ministry of Research Technology and Higher Education Indonesia "KEMENRISETDIKTI" that has been given platform for all Higher Education Students in case of Student Creativity Program "Program Kreativitas Mahasiswa (PKM)".

\section{REFERENCES}

[1] Sasanipour, J., Saeedi, M., Baghban, A., \& Mansoori, H. 2017. "Modeling of wax deposition produced in the pipelines using PSOANFIS approach". Petroleum Science and Technology, pp 19741981.

[2] Cox, L. J. 2008. "What's Wrong with Risk Matrices? Risk Analysis", 28

[3] Hermawan, L., Subiyono, S., H., Rahayu, S., 2012. "Pengaruh Pemberian Asupan Cairan (Air) Terhadap Profil denyut Jantung Pada Aktivitas Aerobik", Journal of Sport Sciences and Fitness, Vol 1 (2), pp 14-20.

[4] Alametsä, J., Palomäki, A., Viik, J. 2012. "Carotid and radial pulse feature analysis with EMFi sensor". Finish Journal of eHealt and eWelfare, Vol 4 (2), pp 80-88.

[5] National Health Service. 2018. How do I check my pulse. Available at: https://www.nhs.uk/common-health-questions/accidents-firstaidandtreatmen ts / how-do-i-check-my-pulse/ [Accessed 25 May 2019] 60-100 bpm normal +"See GP for $r / v$ if HR is continuously above $120 \mathrm{bpm}$ or below $40 \mathrm{bpm}$, although it may simply be that this is normal for you" 